\title{
Open Access Beyond Article Processing Charges
}

\author{
A comment on "For NGOs, article-processing charges sap conservation \\ funds" by Wood et al.
}

Olivier Pourret, UniLaSalle, France https://orcid.org/0000-0001-6181-6079

Ksenija Bazdaric, Rijeka University Faculty of Medicine, Croatia https://orcid.org/0000-0002-2977-3686

Lonni Besançon, Monash University, Australia https://orcid.org/0000-0002-7207-1276

Monica Gonzalez-Marquez, Independent, Germany, https://orcid.org/0000-0002-5114-9599

Jo Havemann, Access 2 Perspectives, Germany https://orcid.org/0000-0002-6157-1494

David William Hedding, University of South Africa, South Africa https://orcid.org/0000-0002-9748-4499

Andrew Hursthouse, University of the West of Scotland, UK https://orcid.org/0000-0003-3690-2957

Dasapta Erwin Irawan, Institut Teknologi Bandung, Indonesia https://orcid.org/0000-0002-1526-0863

Daniel Enrique Ibarra, Brown University, USA https://orcid.org/0000-0002-9980-4599

Paola Masuzzo, Institute for Globally Distributed Open Research and Education (IGDORE)

https://orcid.org/0000-0003-3699-1195

Sandersan Onie, Emotional Health for All, Indonesia \& Black Dog Institute, Australia

https://orcid.org/0000-0003-2147-8102

Joy Owango, Training Centre in Communication/AfricArxiv, Kenya https://orcid.org/0000-0002-3910-2691

Charlotte Wien, University Library of Southern Denmark, Denmark https://orcid.org/0000-0002-3257-2084

* all but the first author are in alphabetical order

Heads of states and various stakeholders have convened at COP26 to formulate solutions to the impacts of climate change. Addressing these enormous challenges requires access to scientific research, including that conducted by environmental non-government organizations (eNGOs). The problem is that most of this urgently needed, and government and donation funded research, remains locked behind publisher paywalls. The Open Science movement emerged in recognition that the challenges of the century are immense and require that science be open and accessible to all (e.g., Mertens and Brown, 2021; Marsh and Badzaric, 
2021). It is crucial that all stakeholders have unfettered access to scientific information, and that scientists are able to not only disseminate research but have access to interconnected and high-quality repositories of knowledge to advance our understanding of the world, democratize knowledge, and face these challenges successfully (Figure 1).

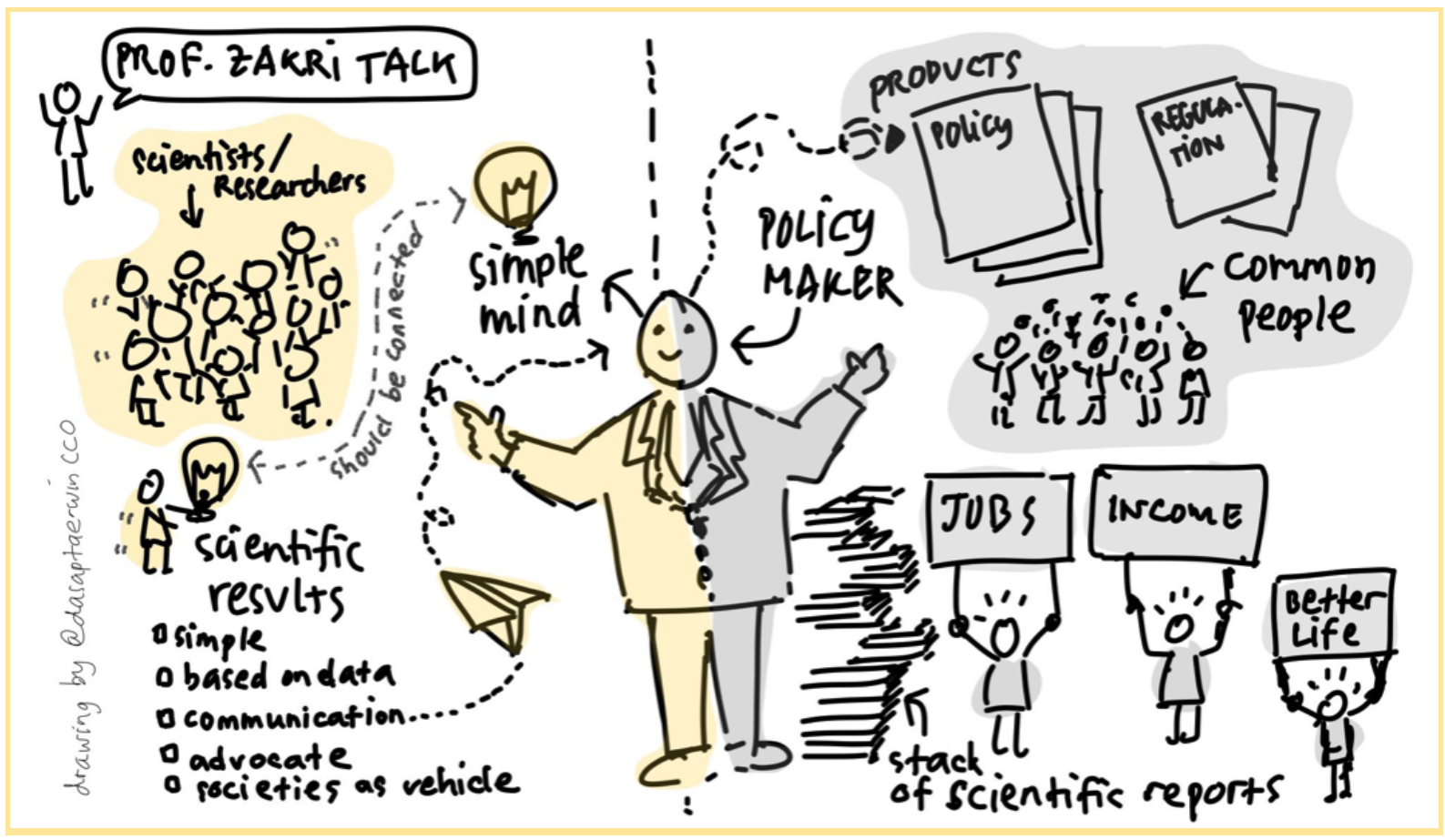

Figure 1 Sketchnote drawn by Dasapta Erwin Irawan on Professor Zakri's talk at SEANOS event (October 2021 https://sciencesea2021.com/). This talk touched on the importance of the impact of research as the basis of decisions taken by policy makers. In this session, he pointed out that aside from the admitted burden of "publish and/or perish", researchers should not limit their outputs to journal publishing. Indeed, the impact agenda is also one additional challenge for the modern academic, translating good quality research into information for policy makers that is understood is critical and often weakly carried out.

In a recent correspondence article, Wood, Newth and Hilton (2021) point to the dilemma where environmental non-governmental organisations (eNGOs) often find themselves having to "now choose between taking conservation action and publishing more research papers". At issue are the ever-increasing article-processing charges (APC) of highly visible scientific journals, and the paucity of alternatives to reaching a broad audience. We argue 
Preprint not peer-reviewed

that often overlooked but impactful alternatives do exist, and that they allow researchers of any discipline, as well as eNGOs, to successfully disseminate their findings.

We very much agree with Wood et al. (2021) that "the shift from a 'reader pays' to an 'author pays' model of scientific publishing presents a financial threat to eNGOs" as well as the global scientific community at large. The authors ask for "a more equitable publishing system" and argue that platinum and diamond open access (OA), financed by third parties such as scientific societies, avoid APCs for authors and paywalls for readers, and as such can offer the lowest-cost option. According to the Directory of Open Access Journals (https://doaj.org/), in 2020 around $69 \%$ of fully OA journals do not levy APCs; although, perhaps counter-intuitively, $65 \%$ of articles published OA are published in journals with APCs (Crawford, 2021). This apparent contradiction is due to two factors, both tied to the currency of career advancement: publication and citations . (i) The need for authors to publish in high impact journals for career advancement. Although most high-impact journals remain paywalled, they have added an open access option whereby authors pay APCs to make their work open access. In this way, authors can ensure the accessibility of their work to all interested parties AND satisfy career constraints. But they can only do so at a very high cost. APCs at traditionally paywalled journals can range from 1500-10,000 Euros. These are substantial sums, especially when taking into account the costs of doing the actual research, in this case, environmental work, much of which is funded by public donations. (ii) Visibility is another key factor. The argument is that gold open access is well and good, but ultimately useless if no one knows that your work exists. For all their faults, high impact paywalled journals have a great deal of visibility, thus facilitating knowledge of the work by potential consumers, and hence, citation. Their vision is, however, only partial. Like many authors, they describe a misconception that OA restricts author choice via APCs.

In reality, 'green OA' alleviates many of the risks the authors mention. Green OA involves self-archiving of work directly by its authors (usually the accepted manuscript or 'postprint', prior to any typesetting or copy-editing by the publisher) on a personal website or 
Preprint not peer-reviewed

general-purpose repository (e.g., EarthArXiv for Earth, environmental and planetary sciences, AfricArXiv and RINarxiv for African and Indonesian research output, respectively) or institutional repository. Significantly, this approach opens up both the production of and access to research by researchers and policymakers who work outside of academia, such as those from eNGOs and who collectively form a critical component of international conferences such as COP 26.

Many countries (Denmark, Ethiopia, France, Indonesia, Netherlands, UK, to cite a just few) have national regulations which encourage or even mandate that the authors' version is uploaded to suitable repositories (see OA archiving policies for journals at:

https://v2.sherpa.ac.uk/romeo/ ). As such, this does not constrain researchers in their choice of publishing outlet, as virtually all environmental sciences journals allow this or even deposit articles automatically (sometimes after an embargo period).

Green OA has many advantages (Suber, 2012). It provides quick and often free publishing routes, while being much more affordable for libraries and funders to maintain/support. Quality assurance is also provided because not two or three but rather hundreds and thousands of researchers can help in community-driven peer review while the results can feed into informed discussions for policymakers and industry leaders to develop solutions (Tennant et al., 2006). Green OA can be mandated without infringing academic freedom. A green OA policy at a university or a country can cover the institution's entire research output, regardless of where authors choose to publish. Moreover, green OA is compatible with paywalled publication. Well-drafted OA policies can ensure that authors always retain the needed rights and spare them the need to negotiate with publishers. Even when the most prestigious journals in a field are placed behind a paywall, green OA allows authors to have their cake and eat it too. Preprints protect the authors' intellectual copyright (Tennant et al., 2019). Preprints and journal articles enable researchers to disseminate their findings to the research community; they are complementary in that preprints represent an opportunity to disseminate at an early stage. Green OA is the more equitable way of publishing as it allows 
Preprint not peer-reviewed

researchers from Latin America, Africa, SE Asia, and eNGOs, to contribute without monetary obstacles.

Visibility and salience remain a question by the authors. Regardless of what the reality of impact factors might be, it is true that they enjoy high visibility. This is a major weakness of the current green OA model. All articles should be accessible by anyone, but people, e.g. government officials, first need to know an article exists to want to access it (Pourret et al., 2020). The solution therefore is two-fold. First, we need a campaign to educate consumers of scientific information, e.g. public policy, etc. about the full-spectrum of sources of scientific information. Such an education campaign would present paywalled journals as only one option among many, and should include information on accessing supporting materials such as data sets. Second, an additional campaign must be put in place to improve dissemination among green and gold access sources. It should involve alternate dissemination models that emphasize the openness of the information, thus not only improving upon the quality of dissemination, but also setting apart green and gold access sources as the superior choice.

Given the current publishing landscape, we recommend that researchers working in, for or with eNGOs move away from the common practices in research assessment of their colleagues working in the universities. We encourage them to extend their research practices to community-led peer-reviewing and dissemination. Additionally, community Peer Review services and platforms such as Peer Community In (https://peercommunityin.org/), PreReview (https://prereview.org/), and ASAPbio (https://asapbio.org/) could jointly be consulted in the eNGO scientific publishing ecosystem. Moreover, eNGO researchers should also set examples in FAIR (Findable, Accessible, Interoperable, and Reusable) data sharing using subject specific open data repositories (see a list there https://www.nature.com/sdata/policies/repositories). Other general repositories (e.g. Zenodo) can be used, as also regional/national-level data repositories (e.g. r3data portal for European institutions, and RIN for Indonesian). 
Preprint not peer-reviewed

In an era where all publishers propose OA solutions, it is up to us, researchers and policy makers, to make sure we favor free-of-charge solutions when they exist. These choices underline that scientific information is a publicly funded human endowment, and that it should be treated as such.

Authors' contributions Olivier Pourret: Conceptualization, Writing - original draft, Writing review \& editing; Dasapta Erwin Irawan: Visualization, Writing - original draft, Writing - review \& editing; all other authors: Writing - original draft, Writing - review \& editing.

\section{References}

Crawford W. (2021) GOAJ6: Gold Open Access Journals 2015-2020; Cites \& Insights Books: Livermore, CA, USA.

Marsh J, Bazdaric K (2021) Climate change and health: the role of journals and editors. European Science Editing 47: e75635. https://doi.org/10.3897/ese.2021.e75635

Mertens S, Brown A (2021) Environmental sustainability and scientific publishing: EASE manifesto. European Science Editing 47: e75625. https://doi.org/10.3897/ese.2021.e75625

Pourret O, Suzuki K, Takahashi Y (2020) Our Study is Published, But the Journey is Not Finished! Elements 16: 229-230. https://doi.org/10.2138/gselements.16.4.229

Suber P (2012) Open Access: MIT Press. 242.

Tennant JP, Waldner F, Jacques DC, Masuzzo P, Collister LB, Hartgerink CHJ (2016) The academic, economic and societal impacts of Open Access: an evidence-based review. F1000Research 5:632 https://doi.org/10.12688/f1000research.8460.3

Tennant JP, Crane H, Crick T, Davila J, Enkhbayar A, Havemann J, Kramer B, Martin R, Masuzzo P, Nobes A, Rice C, Rivera-López B, Ross-Hellauer T, Sattler S, Thacker PD, 
Preprint not peer-reviewed

Vanholsbeeck M (2019) Ten Hot Topics around Scholarly Publishing. Publications 7(2):34.

https://doi.org/10.3390/publications7020034

Wood K.A., Newth J.L., Hilton G.M. (2021) For NGOs, article-processing charges sap

conservation funds. Nature 599: 32 https://doi.org/10.1038/d41586-021-02979-5 